\title{
FR-900148, A NEW ANTIBIOTIC
}

\section{STRUCTURE DETERMINATION OF FR-900148}

Yoshio Kuroda, Masakuni Okuhara, Toshio Goto, Masanori Okamoto, Michio Yamashita, Masanobu Kohsaka, Hatsuo Aoki and Hiroshi Imanaka Research Laboratories, Fujisawa Pharmaceutical Co., Ltd., Osaka, Japan (Received for publication December 7, 1979)

The structure of FR-900148, a new antibiotic produced by a strain of Streptomyces xanthocidicus, has been established as 1-N-valyl-3-chloro-2,5-dihydro-5-oxo-1H-pyrrole-2carboxylic acid on the basis of spectroscopic and chemical evidence.

In the course of screening for cell wall inhibitors, we found that a strain of Streptomyces xanthocidicus produces an antibiotic. The product, designated FR-900148, shows activity against Grampositive as well as Gram-negative bacteria, although Pseudomonas aeruginosa is not inhibited. The taxonomy of the producing organism, and procedures for isolation and characterization of FR-900148 have been reported in a preceding paper ${ }^{1}$. This paper describes elucidation of the structure of FR900148.

\section{Results and Discussion}

FR-900148 (I) was isolated as an amphoteric white powder [sodium salt: m.p. $143 \sim 147^{\circ} \mathrm{C}$ (decomp.)]. The antibiotic shows $\mathrm{pKa}^{\prime}$ values of 3.25 and 7.90 , and is soluble in water and methanol. Its Rf value is 0.65 on silica-gel thin-layer plates developed with $n$-propanol - water (6: 4). The antibiotic was detected by its positive reaction with ninhydrin. Elemental analysis and titration of $\mathbf{I}$ established the molecular formula as $\mathrm{C}_{10} \mathrm{H}_{12} \mathrm{~N}_{2} \mathrm{O}_{4} \mathrm{Cl} \mathrm{Na} \cdot 2 \mathrm{H}_{2} \mathrm{O}$. The IR spectrum exhibited absorption bands attributable to an amide group and double bond at $1500 \sim 1700 \mathrm{~cm}^{-1}$ and to $\mathrm{C}-\mathrm{Cl}$ at $670 \mathrm{~cm}^{-1}$. The pmr spectrum showed the following signals; six methyl protons, three methine protons and one olefinic proton (see the preceding paper $\left.{ }^{1)}\right)$. The signals at $\delta 1.04(3 \mathrm{H} \times 2, \mathrm{~d}, \mathrm{~J}=7 \mathrm{~Hz}), 2.25(1 \mathrm{H}, \mathrm{m})$, and 3.92 $(1 \mathrm{H}, \mathrm{d}, \mathrm{J}=7 \mathrm{~Hz})$ are assigned to a valyl residue. A decoupling experiment supported the presence of valine.

The reactions described below are outlined in Scheme 1. Hydrogenation of $\mathbf{I}$ consumed two moles of hydrogen and the reaction solution had a $\mathrm{pH}$ of 2.0. This is attributed to the hydrochloric acid liberated in the reaction. The hydrogenated product (II) was subjected to acid hydrolysis which afforded valine (III) and glutamic acid (IV). The pmr of II also indicated that II is valyl glutamic acid (Fig. 1). Because $\mathbf{I}$ has only one $\mathrm{pKa}^{\prime}$ at 3.25 in the acidic region, it is believed to contain a cyclic glutamic acid structure (pyro-glutamic acid).

Treatment of $\mathbf{I}$ with acetic anhydride and subsequent methylation with diazomethane gave an $\mathrm{N}$-acetyl methyl derivative (VII). Considering that the fragment left in $\mathbf{I}$ after accounting for valine is $\mathrm{C}_{5} \mathrm{H}_{2} \mathrm{NO}_{3} \mathrm{Cl} \mathrm{Na}$ and that glutamic acid was obtained by hydrogenation, the partial structure of $\mathbf{I}$ should be one of the three shown in Fig. 2 (VIII $\sim \mathbf{X})$. The pmr spectrum of $\mathbf{I}$ shows signals at $\delta 4.98$ 
Scheme 1.

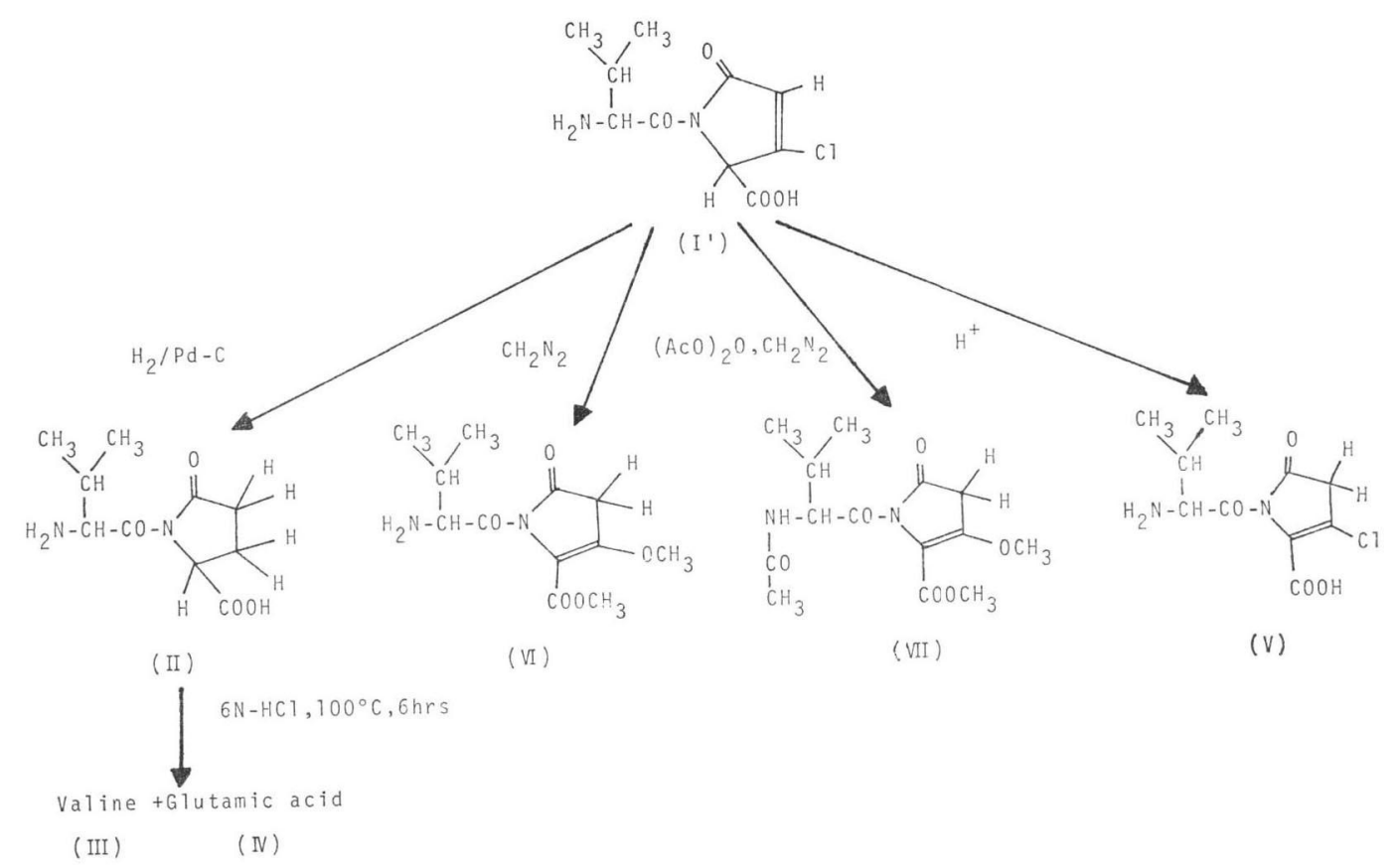

$(1 \mathrm{H}, \mathrm{s})$ and $\delta 6.46(1 \mathrm{H}, \mathrm{s})$ in addiFig. 1. Pmr spectrum of compound $\mathrm{II}\left(\mathrm{D}_{2} \mathrm{O}\right)$. tion to those attributed to valine. Structures IX and $\mathbf{X}$ are excluded since signals corresponding to their two protons should be observed as doublets and as an $\mathrm{AB}$ system or singlet, respectively. Thus, VIII is the most probable structure. Theoretical calculations of $\delta$ values for $\mathrm{C}_{4}-\mathrm{H}$ of VIII gave $\delta 6.54^{2)}$, which is in good agreement with the observed value ( $\delta 6.46)$.

Treatment of I with mild acid gave the biologically inactive compound (V), which showed a molecular ion peak at $260\left(\mathrm{M}^{+}\right)$and 262 $(\mathrm{M}+2)$ in the mass spectrum (peak height ratio, $3: 1$ ). Elemental analysis established the molecular for-

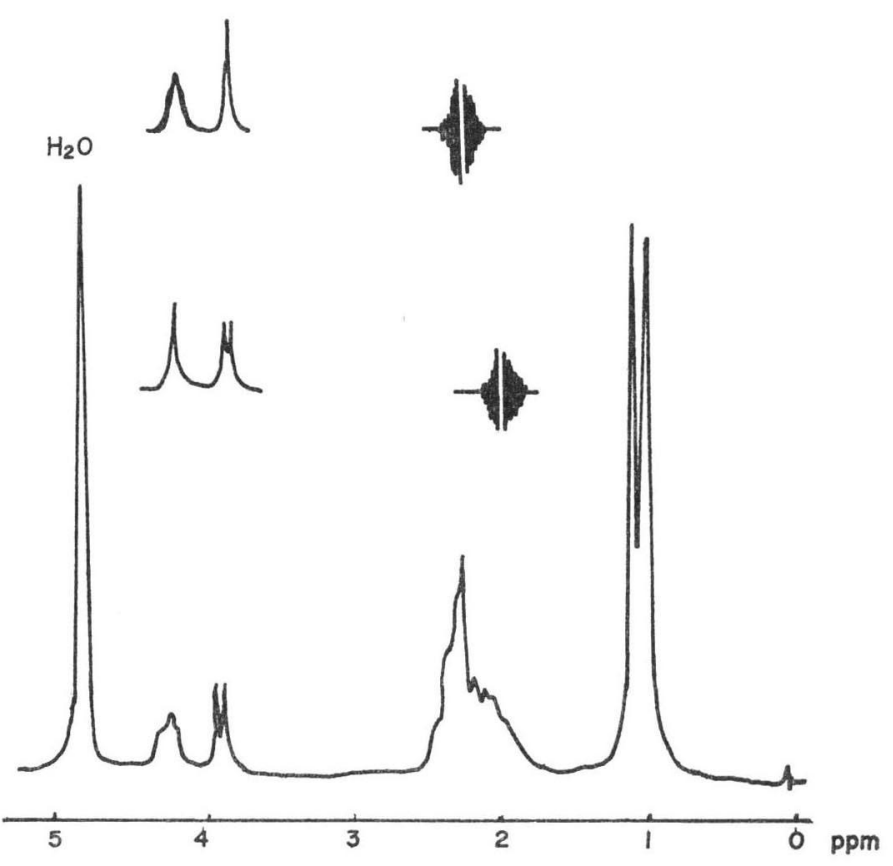
mula as $\mathrm{C}_{10} \mathrm{H}_{13} \mathrm{~N}_{2} \mathrm{O}_{4} \mathrm{Cl}$. The pmr spectrum indicated that isomerization had occurred as shown in Scheme 1. The free acid of $\mathbf{I}\left(\mathbf{I}^{\prime}\right)$ was methylated with diazomethane to give compound VI, for which the molecular formula $\mathrm{C}_{12} \mathrm{H}_{18}$ $\mathrm{N}_{2} \mathrm{O}_{5}$ was indicated by elemental analysis and mass spectrometry $\left(\mathrm{M}^{+} 270\right)$. Compound VI contains no 
Fig. 2. Partial structure of FR-900148.<smiles>[R]OC(=O)N1C(=O)C=CC1Cl</smiles>

(VII)

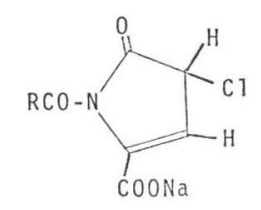

( IX)<smiles>[R]C(=O)N1C(=O)C(C)C(Cl)=C1Cl</smiles>

$(x)$

Fig. 3. Pmr spectrum of compound VI $\left(\mathrm{CDCl}_{3} / \mathrm{D}_{2} \mathrm{O}\right)$.

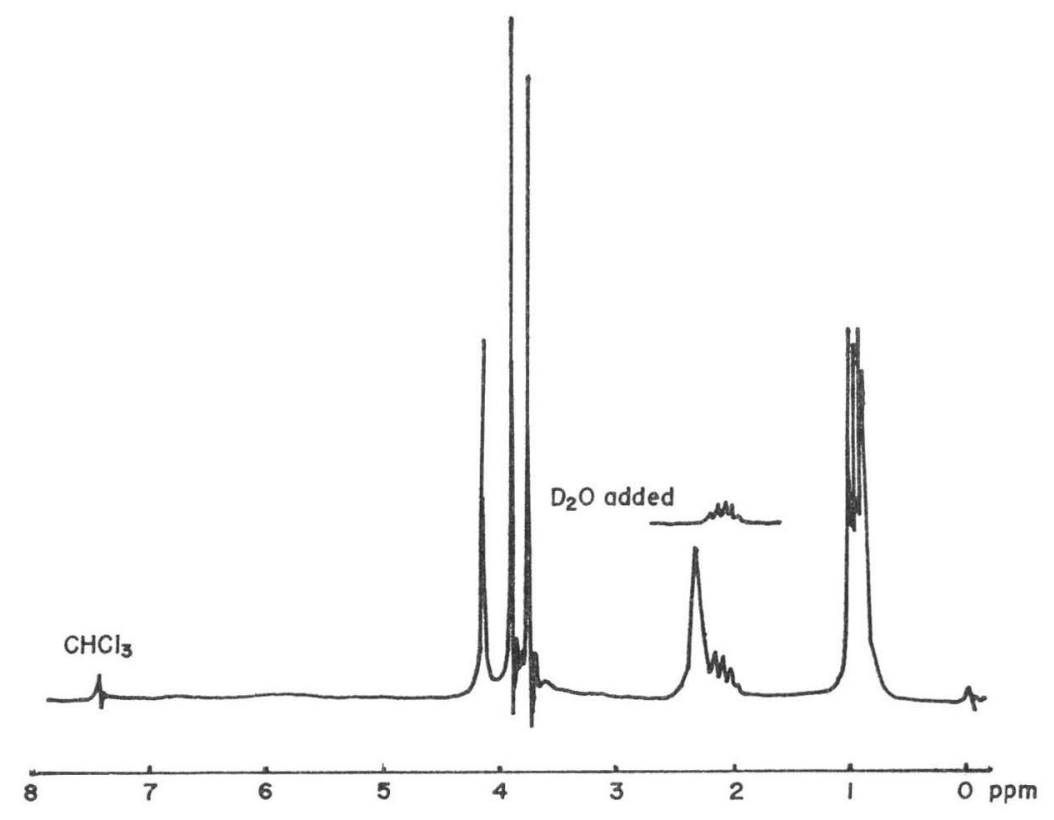

Fig. 4. Methylation of FR-900148-free acid with diazomethane.

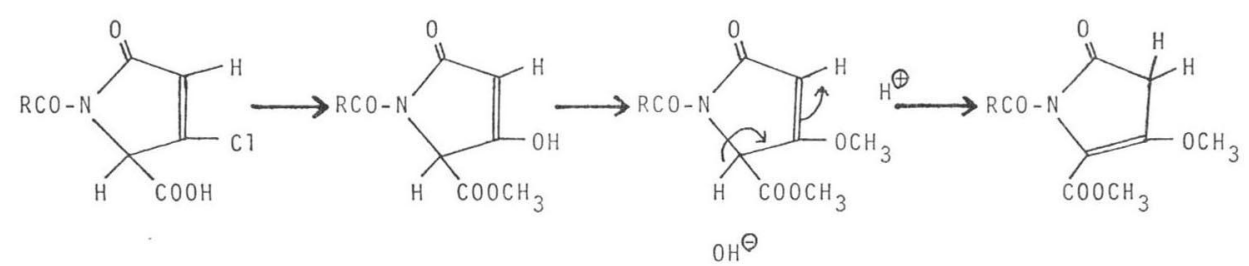

chlorine and its pmr spectrum showed two methoxy groups (Fig. 3). The signals at $\delta 4.98$ and $\delta 6.46$ in I have coalesced to a two-proton singlet at $\delta 4.10$. The same phenomenon was observed upon mild acid treatment of $\mathbf{I}$. The mechanism proposed for this methylation (Fig. 4) involves hydrolysis of the vinyl chloride to give an enol. The enol is then methylated and the product isomerizes.

The ${ }^{13} \mathrm{C}$-nmr spectrum of I (Fig. 5) is consistent with the proposed structure. Chemical shifts are assigned (Table 1 ) on the basis of predicted values in conjunction with the results of ${ }^{1} \mathrm{H}$ off-resonance experiments. Consequently, the structure deduced for FR-900148 is 1-N-valyl-3-chloro-2,5-dihydro5-oxo-1H-pyrrole-2-carboxylic acid. Synthetic studies are now in progress. 
Fig. 5. ${ }^{13} \mathrm{C}-\mathrm{Nmr}$ spectrum of FR-900148 $\left(\mathrm{D}_{2} \mathrm{O}\right)$.

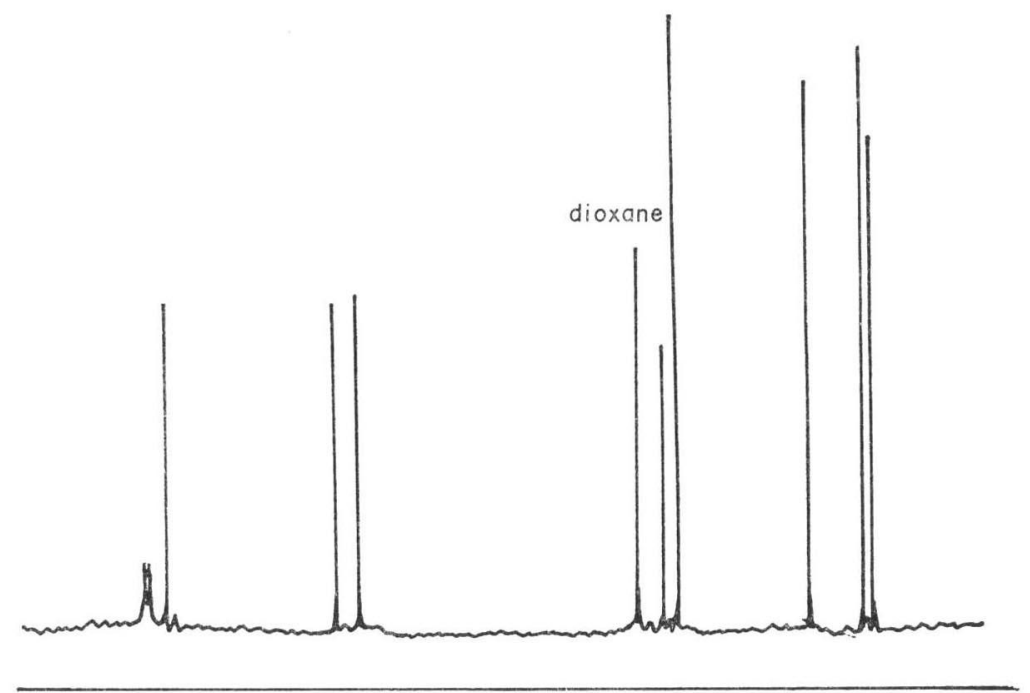

Experimental

(1) Material

FR-900148 (I) was obtained from the fermentation broth of Streptomyces xanthocidicus by the methods described in the preceding paper which also reports spectral and chemical char$\operatorname{acteristics}^{1)}$.

(2) Hydrogenation

A $400 \mathrm{mg}$ sample of I in $40 \mathrm{ml}$ of $50 \%$ aqueous ethanol was hydrogenated over paladium-carbon at $20^{\circ} \mathrm{C}$ under one atmosphere of hydrogen. Two moles of hydrogen were absorbed within 2 hours. The $\mathrm{pH}$ of the reaction solution fell to 2.0 and was adjusted to 6.5 with $6 \mathrm{~N} \mathrm{NaOH}$. After concentration, the hydrogenation reaction mixture was desalted by the use of Sephadex G-15 (1.5 liters). Concentration and freeze-drying of the ninhydrin-positive fraction gave $300 \mathrm{mg}$ of white powder (II). Compound $\mathbf{I}$ showed an $\mathrm{Rf}$ value of 0.6 when developed on a silica gel $\mathrm{G}$ plate with $n$-propanol - water (6:4).

Analysis Calcd. for $\mathrm{C}_{10} \mathrm{H}_{15} \mathrm{~N}_{2} \mathrm{O}_{4} \mathrm{Na} \cdot \mathrm{H}_{2} \mathrm{O}$ :

$\mathrm{C} 44.78, \mathrm{H} 6.34, \mathrm{~N} 10.45, \mathrm{Cl} 0.00, \mathrm{Na} 8.58$

Found: $\mathrm{C} 44.22, \mathrm{H} 6.94, \mathrm{~N} 9.97, \mathrm{Cl} 0.03$, Na 7.90

$\operatorname{Pmr}\left(\mathrm{D}_{2} \mathrm{O}\right): \quad \delta 1.04(3 \mathrm{H} \times 2, \mathrm{~d}, \mathrm{~J}=7 \mathrm{~Hz}), 1.80 \sim 2.40(5 \mathrm{H}, \mathrm{m}), 3.84(1 \mathrm{H}, \mathrm{d}, \mathrm{J}=7 \mathrm{~Hz})$, and $4.20(1 \mathrm{H}, \mathrm{m})$.

(3) Hydrolysis of compound II

A solution of $50 \mathrm{mg}$ of $\mathrm{II}$ in $6 \mathrm{~N} \mathrm{HCl}$ was refluxed at $100^{\circ} \mathrm{C}$ for 6 hours, and concentrated to dryness in vacuo. Two ninhydrin-positive substances were detected by TLC on cellulose with $n$-butanol acetic acid - water (4:1:1) as developing solvent. They were identified as valine (III) and glutamic acid (IV) by comparison of their $\mathrm{Rf}$ values with those of authentic samples. 
(4) Treatment of I with mild acid

A solution of $500 \mathrm{mg}$ of $\mathbf{I}$ in acidic water $(\mathrm{pH} 2.0,50 \mathrm{ml})$ was kept at $20^{\circ} \mathrm{C}$ for 3 days. Concentration of this solution yielded $450 \mathrm{mg}$ of colorless crystal $(\mathbf{V})$.

Analysis Calcd. for $\mathrm{C}_{10} \mathrm{H}_{13} \mathrm{~N}_{2} \mathrm{O}_{4} \mathrm{Cl} \cdot \mathrm{H}_{2} \mathrm{O}$ :

C $43.16, \mathrm{H} 5.40, \mathrm{~N} 10.07, \mathrm{Cl} 12.59$

Found: $\quad$ C $42.82, \mathrm{H} 5.50, \mathrm{~N} 10.05, \mathrm{Cl} 12.62$

Mass spectrum: $m / e 260(\mathrm{M}), m / e 262(\mathrm{M}+2)$

$\mathrm{NMR}\left(\mathrm{D}_{2} \mathrm{O} / \mathrm{NaHCO}_{3}\right): \quad \delta 1.03(3 \mathrm{H} \times 2, \mathrm{~d}, \mathrm{~J}=7 \mathrm{~Hz}), 2.15(1 \mathrm{H}, \mathrm{m}), 3.65(2 \mathrm{H}, \mathrm{s})$, and $3.95(1 \mathrm{H}, \mathrm{m})$

(5) Methylation

A solution of $600 \mathrm{mg}$ of $\mathbf{I}$ in $30 \mathrm{ml}$ water was passed through a CM-Sephadex column $\left(\mathrm{H}^{+}\right.$cycle $)$ in order to prepare the free acid $\left(\mathbf{I}^{\prime}\right)$. To this solution was added $100 \mathrm{ml}$ of methanol and then ethereal diazomethane at $20^{\circ} \mathrm{C}$ until the yellow color of diazomethane did not disappear. The reaction mixture was concentrated and purified by chromatography on a silica gel column with ethyl acetate methanol (10:1) as eluant. Fractions giving positive ninhydrin reactions were collected and concentrated to give $300 \mathrm{mg}$ of colorless oil (VI).

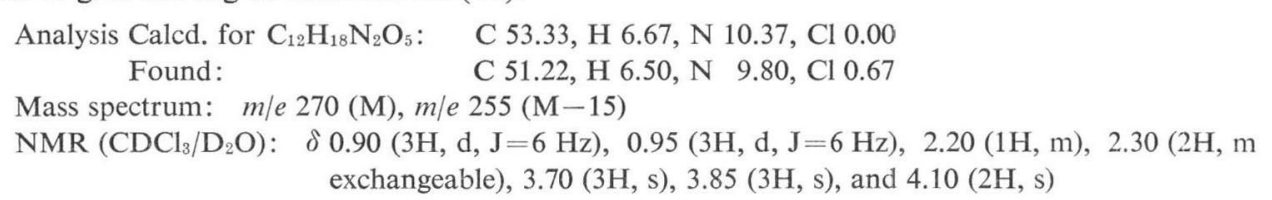

(6) Acetylation and methylation

To a solution of $400 \mathrm{mg}$ of $\mathbf{I}$ in $10 \mathrm{ml}$ of $50 \%$ aqueous methanol was added $0.7 \mathrm{ml}$ of acetic anhydride. The mixture was stirred vigorously at $20^{\circ} \mathrm{C}$ for 2 hours at $\mathrm{pH} 8.0$, then concentrated and diluted with water to give $20 \mathrm{ml}$ of aqueous solution. After adjustment to $\mathrm{pH} 2.0$, the acetylated compound was extracted with an equal portion of $n$-butanol. Methylation was carried out by the addition of ethereal diazomethane. The methyl ester was purified by silica gel chromatography using ethyl acetate as eluant and iodine vapor for detection. Concentration of the positive fractions gave $400 \mathrm{mg}$ of colorless oil (VII).

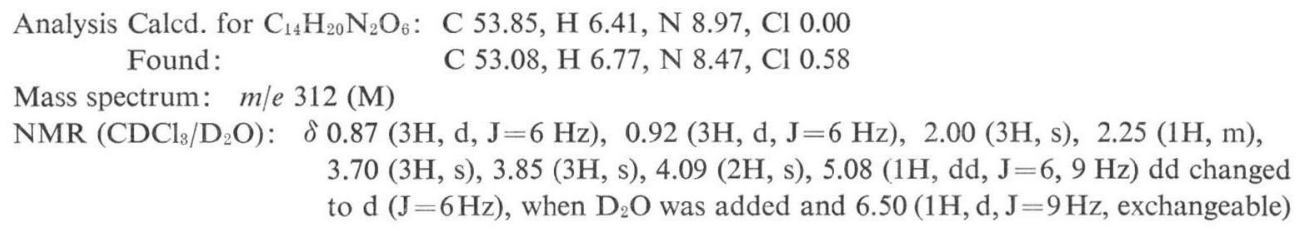

Acknowledgement

The authors are indebted to Dr. M. Hashimoto and Dr. H. TANAKA for their valuable discussions and suggestions during this work.

\section{References}

1) Kuroda, Y.; M. Okuhara, T. Goto, M. Yamashita, E. Iguchi, M. Kohsaka, H. Aoki \& H. Imanaka: FR-900148, a new antibiotic. I. Taxonomy, fermentation, isolation and characterization. J. Antibiotics 33: $259 \sim 266,1980$

2) Jackman, L. M. \& S. Sternhell: Applications of nuclear magnetic resonance spectroscopy in organic chemistry. 2nd edition, p. 184, Pergamon Press, London, 1969 